\title{
Technological innovations and the effect of 'dualism'
}

\author{
Oleg Sukharev* \\ Institute of Economics of the Russian Academy of Sciences, 117218 Nakhimovsky prospect, 32, Moscow, Russia
}

\begin{abstract}
The purpose of the research is to consider the effect of technological dualism for the Russian economy with an empirical demonstration that this effect has a different content. The research methodology consists of the neo-Schumpeterian theory of technological change, structural analysis, and empirical estimates that allow one to identify the characteristics of technological dynamics. The result of this research was a demonstration of the deviation from the classical effect of technological dualism of the Russian economy, which is caused by the existing structural and institutional characteristics of the functioning of activities various types. The main conclusion is that the classical recipes for stimulating technological innovation in the presence of the pseudo-effect of technological dualism will not become working tools with high action. We need systemic and institutional transformations that affect the incentives for technological renewal and the deployment of markets that accept products that embody the results of technological improvement and development. Thus, replacing the strategy of local technological innovations with a strategy of comprehensive incentives and large-scale technological innovations that improve the social parameters of life is an urgent task for the Russian economy.
\end{abstract}

\section{Introduction}

Technological innovations occupy the main place in the structure of innovations, largely determining further product, process and organizational innovations. From the point of view of Schumpeter's theory of development $[1,3,5,7-9,11]$, technological innovations follow the logic of the effect of 'creative destruction' and 'combinatorial augmentation' [2,9]. Moreover, in 'creative destruction' some technological innovations displace other, when you 'combinatorial augmentation' of the integration of technology, but not usually in the form of coexistence of NBIC - technologies, as illustrative examples for combinatorics, and in the form of a new technological quality. Thus, the use of different technologies gives a completely different technological chain in the form of technological innovation. This is the fundamental difference between the scientific works of a number of authors, in particular, representatives of the Russian neo-Schumpeterian school [2] and the foreign neo-Schumpeterian school [9], which show the content and influence on the development of the combinatorial effect. However, in addition to the combinatorial effect, Schumpeter combinations compete with each other within each allocated group, as well as between groups, since, for example, technological innovations determine not only the product or processes, but also organizational changes and management. Thus, the overall structure of technologies represents a dynamically and flexibly changing technological framework of the economy. Moreover, along with the strengthening of technological influence within the framework of the combinatorial effect, there is also a competition of technologies, when some displace others. Labour-saving technologies (in the form of robots, artificial intelligence, computers, automata) displace labour that requires placement within the framework of labour-intensive technologies. Capitalsaving technologies-provide an increase in the return on the capital used. In principle, they can take part of the labour released by labour-saving technologies. At the same time, the problem of labour placement in the field of labour-intensive technologies remains. The dynamic balance between the capital-intensive technologies of the manufacturing sectors and the labour-intensive technologies of other types of activity, which makes it possible to use the released labour force, is the classic content of the effect of technological dualism. It boils down to the co-existence of two classes of capitalintensive and labour-intensive technologies. The former release labour, the latter accept it. Thus, technological unemployment is levelled. With this adsorption of labour in the field of labour-intensive activities, there are objective restrictions for the introduction of laboursaving technologies in these sectors that accept the released personnel. Types of activities with capitalintensive technologies, such as recruitment, introduce labour-saving technologies that simultaneously increase the return on capital. This structural dynamics is determined by the initial technological parameters of the economy, but it also forms the vector of further structural and technological changes. Capital-intensive technologies have a labour-saving effect, cause technological unemployment and act in the direction of not increasing the level of income. The peculiar antisocial effect of such technologies is associated with a positive effect and the motive of the owner of the means

*Corresponding author: o_sukharev@list.ru 
of production and this technology. Institutionally, this contradiction is not removed in any way, with the exception of technological dualism. The issues of equalization of technological effects both in the sectorial structure and in the interstellar structure (dependence on technology transfer) can't be considered fully resolved in economic science. This area of research has immanent uncertainty and practical multivariance, which makes it difficult to obtain accurate model solutions. Some aspect usually is not taken into account. Of course, the macroeconomic policy can also strongly influence the process of technological renewal and the technological structure. The relatively high cost of capital, even if it is highly worn out, will clearly hinder the introduction of capital-intensive and labour-saving technologies. The level of science and education provides an opportunity to learn new technologies and put them into production. Dualism can take on a very peculiar appearance when the technologies being developed are very different from those implemented and used. Independent structural dynamics, outside the technological context, expressed in the movement of labour from processing to other sectors of the economy (raw materials, services), accompanied by the compressed development of processing activities, can also hinder technological renewal in the direction of the introduction of capitalintensive, labour-saving technologies. Then this circumstance is the reason for the gap between the development and implementation of technologies, when technology can be possessed and have trained personnel, but it is not implemented. The technological gap of implementation is adjacent to the gap in capital-intensive and labour-intensive technologies, which institutionalizes the technological effect of dualism, giving it special characteristics that distinguish the technological dynamics of different countries (the technological structure, as a rule, is initially different).

Let's consider the technological dynamics and features of technological dualism on the example of the Russian economy. The purpose of the study is to identify the specifics of technological dualism for Russia, which forms the features of the dynamics of technological innovations. The research methodology is formed by structural and empirical analysis, application to the evaluation of the development and introduction of the most advanced technologies, which can be used to characterize technological innovations.

\section{Research methodology. Technological dynamics and dualism}

Technological innovations cover improved or completely new technology, and there can be two approaches to novelty. First, the technology may be new for a given organization, but not for the market as a whole, and it is not necessarily that it was developed by this organization. Second, the novelty can be provided for this particular organization, in the absence of a significant number of other organizations that use the same technology. Depending on the accepted form of accounting, as a result, there will be a discrepancy in the estimates of the magnitude of technological innovations. The latter are determined by the state of knowledge [11], however, not always R\&D, high technologies, involving a significant amount of knowledge, determine economic growth $[4,6]$. In addition, the widespread introduction of technological innovations, in particular digital technologies and automation, may not give the effect of productivity growth at all [8], revealing a high dependence on the created initial conditions for application [10] and the state of production technologies.

It should be noted that R\&D does not always end with a positive result, not to mention that it turns into a highly improved or new technology. Of course, the array of $\mathrm{R} \& \mathrm{D}$, after some time, determines the technological possibilities of development, but does not guarantee them. In this regard, it is not entirely convincing and reasonable to evaluate and distinguish the levels of technological activities by the share of R\&D (such estimates are given in particular by Rosstat), since there is no direct relationship between the number of technologies and their level, quality, and volume of R\&D conducted by costs, of course. The topic of the effectiveness of R\&D and its implementation, as well as the development and implementation of technologies, includes an independent set of issues that depend on many circumstances, including the initial parameters of the operation of production. In our opinion, the accounting of technological novelty in its pure form will be most accurate if it is carried out in specific technological areas, types of technologies, adhering to a particular classification of technologies and innovations.

The technological dynamics of the economy can be studied from the perspective of two basic approaches. On the one hand, using an aggregate method that gives a general description of changes in technologies, including by type of technology. On the other hand, it is a structural method that reveals the current technological structure, as well as its impact on the development and other dynamic parameters of the economy, allowing us to assess the contribution of various technologies to the country's economic growth rate. Technological innovations according to the aggregate method can be evaluated by the number of firms and individual agents that implement technological innovations. The structural method of analysis allows to consider the structure of innovations (fundamental, improving, product, process, etc.), the contribution of each type to the growth rate, and the mutual influence of different types of innovations on each other. The whole range of new technologies included in the 'knowledge economy' can be estimated by the share of this sector and its contribution to the rate of economic growth. This will require identifying the "knowledge economy" sector itself along with other sectors in terms of an aggregate indicator, for example, value added, measuring its dynamics and contribution to the overall dynamics. At the same time, a separate task can be formulated as identifying the structure of the technologies of the 'knowledge economy' and its impact on the development of both this sector and the economy as a whole, including its dynamics. Of course, the aggregate approach assumes an assessment of technological 
dynamics by the number of different levels of technology development in each type of activity. Building such a structure can give a kind of portfolio of technological development, namely, to show how technologies are distributed within the framework of their unified classification and selected types for various types of economic activity. Such a portfolio, if it is obtained, will allow the distribution of technologies by type of work and technological saturation or concentration, since individual activities will take over most of the total composition of technologies. In particular, such activities, covering, for example, most of the technological innovations, will include processing, industry. Information processing, data retrieval, and financial transaction management technologies will be most common in services, including the financial sector.

Such a portfolio or "technological map" can serve as a reference point in assessing the quality of the technological novelty that arises and is used in the economy. Of course, the aspect of mutual determination of different technologies in different activities will also be very valuable, but its resolution will be facilitated by such a technology map or portfolio. The technological map provides a static view of the current technological structure by type of technology, and the portfolio allows you to set a number of optimization tasks, in terms of finding out the connections and technological dynamics. Portfolio elements are characterized by a certain impact, efficiency, amount of investment, risk, i.e., a set of parameters suitable for further quantitative research, empirical analysis, and model constructions in the framework of the tasks of the "portfolio choice", which in this case allows you to extend the possibility of the 'technology of choice' and development of the economic structure in the strategic dimension.

The technology portfolio or map (the difference between them as between the dynamics and the statics of the structure) also helps to find out the content of the effect of 'technological dualism', specific features for each country. To investigate this effect, including its identification, the following steps are required:

- identify areas of labour with capital-intensive and labour-intensive technologies (types of activities), create a technological map of labour, get a 'technology portfolio', identify firms and agents of innovators and conservatives in each type of activity and in general for the economy;

- to assess the composition of labour in the types of activities and the movement of labour from areas with capital-intensive, labour-saving technologies to the field of labour-intensive technologies;

- determine the amount of technological unemployment, that is, the unemployed part of the labour force due to the introduction of capital-intensive technologies;

- set the dynamics of capital and labour-intensive technologies input, highlighting the gap between the number of developed and implemented technologies;

- establish the number and dynamics of the introduction of advanced technologies, innovators and conservatives, highlighting the activities that they cover the most, and where such development or input is practically absent, with an explanation of the reasons for the current structure.

The final result listed empirical and model estimates (in the case of the creation of econometric models) is not only the identification of the effect of 'technological dualism', but the definition of what form it occurs whether saturating the displacement of labour-intensive technology capital-intensive technologies (or back), or developed a dynamic equilibrium, and they co-exist without displacement (classic content dualism). In the latter case, the dynamics of technological renewal also stabilizes around a certain value and it becomes problematic to accelerate the change of technologies. The proposed method of analyzing technological dynamics allows not only to determine the depth and form of 'technological dualism', but also to identify pseudo-dualism, in which personnel from capitalintensive technologies are released not because of the introduction of new technologies of this class, but because of the loss of competitive positions of existing capital-intensive technologies. They are partially located in the field of labour-intensive technologies, thereby blocking technological renewal in these areas, as they delay the introduction of labour-saving (capitalintensive) technologies. Such input may occur, in particular, with the expansion of the use of digital technologies, but this class of technologies has the effect of increased involvement of the labour serving these technologies. This circumstance becomes a kind of barrier to saving labour, since with the introduction of new technologies, the volume of the object - information processed by them increases, as well as the tasks for using it and the requirements for its final quality multiply. These additional functions expand the applicability of labour.

Technological dualism becomes an institutional barrier for technological renewal, more precisely, for the dynamics of this process, since in some extent this renewal can occur, without a significant change in the structure of technologies at a selected and very short time interval. And the presence of the pseudo-effect of technological dualism fixes a completely different reason in the process of technological renewal - the introduction of technological innovations. The formation of an institutional barrier by the technological structure itself, as well as the pseudo-effect of the movement of resources between activities, makes it difficult to diffuse technologies. The observed technological dynamics is saturated, or is significant, but in the area of low values of overall manufacturability. For countries that are lagging behind in technological development, there is a vicious circle of technological lag.

A standard policy of promoting technological innovation may not break this vicious circle, as it is based on technological dualism or pseudo-effect, which make it difficult to diffuse technologies, and also includes backwardness or dependence in the development of science and education. The presence of a large gap between the created technologies and the implemented ones indicates the difficulty of technological diffusion, no matter where this gap is fixed - in the presence of a low or high number of advanced 
technologies being developed and implemented. Effective technological diffusion clearly implies an insignificant amount of such a gap. This question requires additional research that goes beyond the goal of this paper.

We will show some aspects of the presented methodological approach on the example of the Russian economy, revealing the presence of the pseudo-effect of technological dualism and the presence of significant structural and technological problems that complicate technological diffusion, that is, the penetration of even created technologies into production.

\section{Discussion of the results. Technological changes and dualism in the Russian Economy}

The effect of technological pseudo-dualism in the Russian economy can be easily shown by the example of the movement of personnel from the processing to the transaction and raw materials sectors (Figure 1, above). The technological efficiency of the sectors not only does not increase significantly, but even decreases it. Although the number of new technologies is growing (Table 1). Of course, the existing approaches in the field of statistical accounting don't allow to distinguish between capital-intensive (labour-saving) and labourintensive technologies.
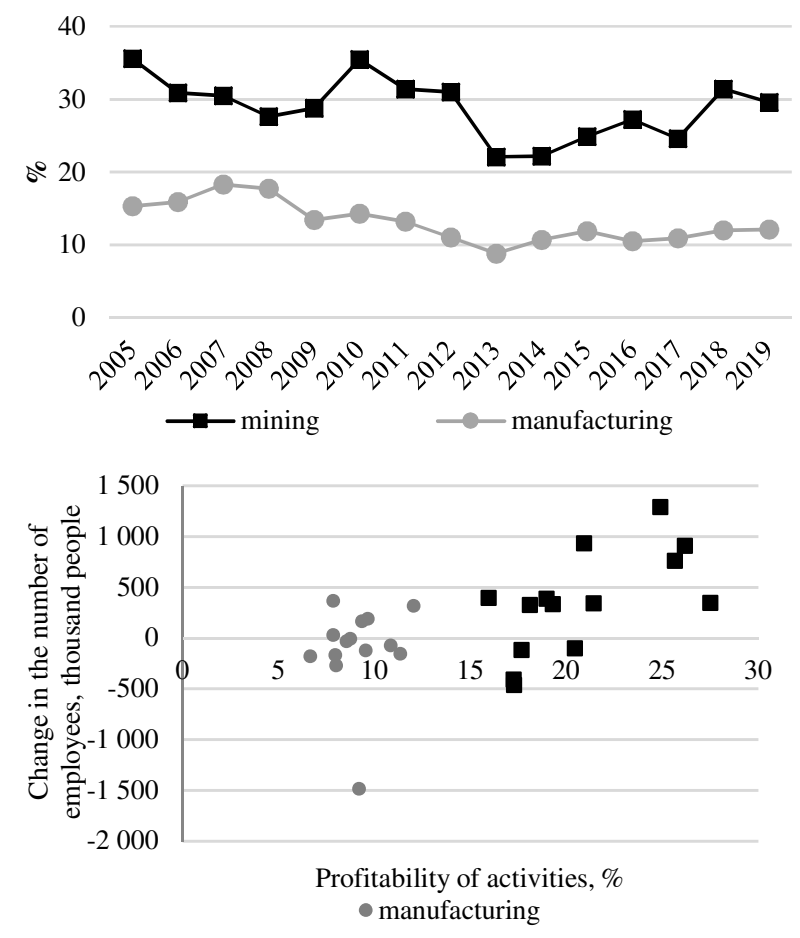

Fig. 1. Profitability of activities (mining and manufacturing), 2005-2019 (above); change in the number of people employed in the manufacturing and transactional and raw materials sector, 2006-2019 (below).

However, the transfer of labour from processing to other types of activity could be associated with the introduction of labour-saving technologies (capital- intensive), but in this case, in theory, the overall technological efficiency should increase, and in particular, this sector. Such a result was not observed in the Russian economy. The high difference in the profitability of mining and processing activities (Figure 1, left), apparently, was the main reason for the movement of labour resources towards the transactional and raw materials sectors. Non-capital-intensive technologies were the reason for the release of labour and its intersectoral movement.

The number of new technologies developed, which are considered advanced, is reflected in the dynamics of Table 1. There is an increase in production of 9 times, in processing - more than 2 times, in the production of machinery and equipment - more than 1.5 times. However, these overall positive figures of technological progress are offset by the presence of the described effect of technological pseudo-dualism, which leads to a slowdown in the creation of fundamentally new technologies (see Table 2). It should be noted that the overall level of adaptability (measured by the ratio of innovative to non-innovative products, works, and services) decreased during the years of increasing the number of these new technologies. This indicates the limited applicability of new technologies. In addition, we can talk about possible accounting problems of assigning emerging technologies to a new class and to fundamentally new advanced technologies.

Table 1. Number of advanced new manufacturing technologies developed for Russia by type of economic activity in Russia, 2010-2019.

\begin{tabular}{|c|c|c|c|c|c|c|c|c|c|c|}
\hline $\begin{array}{c}\text { type of } \\
\text { activity / year }\end{array}$ & $\stackrel{\circ}{\circ}$ & $\overline{\vec{d}}$ & $\stackrel{\text { ㄱ }}{\stackrel{2}{2}}$ & $\stackrel{m}{\frac{n}{2}}$ & $\stackrel{\text { ते }}{\stackrel{7}{2}}$ & $\frac{n}{2}$ & 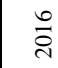 & है & $\stackrel{\infty}{\stackrel{i}{\pi}}$ & $\stackrel{\circ}{\frac{2}{2}}$ \\
\hline mining & 5 & 7 & 12 & 12 & 23 & 17 & 25 & 23 & 21 & 49 \\
\hline$\underset{\mathrm{g}}{\operatorname{manufacturin}}$ & 215 & 320 & 320 & 374 & 382 & 416 & 491 & 409 & 468 & 497 \\
\hline $\begin{array}{l}\text { production of } \\
\text { machinery } \\
\text { and } \\
\text { equipment } \\
\text { (without } \\
\text { production of } \\
\text { weapons and } \\
\text { ammunition) }\end{array}$ & 31 & 34 & 47 & 62 & 31 & 33 & 40 & 37 & 44 & 51 \\
\hline
\end{tabular}

Table 2. The number of fundamentally new developed advanced production technologies by type of activity in Russia, 2010-2019.

\begin{tabular}{|c|c|c|c|c|c|c|c|c|c|c|}
\hline $\begin{array}{c}\text { type of activity } \\
\text { / year }\end{array}$ & $\stackrel{\circ}{\stackrel{i}{*}}$ & $\overline{8}$ & $\frac{\text { ก }}{2}$ & $\frac{\pi}{2}$ & $\frac{\text { त }}{ \pm}$ & $\frac{n}{2}$ & $\frac{0}{2}$ & 륭 & $\stackrel{\infty}{\frac{N}{2}}$ & 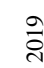 \\
\hline mining & 0 & 3 & 2 & 3 & 2 & 1 & 0 & 0 & 1 & 2 \\
\hline manufacturing & $\begin{array}{l}1 \\
6\end{array}$ & 18 & 16 & 24 & 32 & 26 & 32 & 33 & 34 & 35 \\
\hline $\begin{array}{l}\text { production of } \\
\text { machinery and } \\
\text { equipment } \\
\text { (without } \\
\text { production of } \\
\text { weapons and } \\
\text { ammunition) }\end{array}$ & 3 & 8 & 3 & 2 & 13 & 1 & 0 & 0 & 0 & 1 \\
\hline
\end{tabular}

Source: [12] 
Table 2 shows the changes in fundamentally new production technologies that have been developed in these types of activities in Russia over a ten-year period. In the field of civil production of machinery and equipment, the dynamics of technology development is not stable, and since 2015 there has been almost no positive movement in this area. Although manufacturing industries as a whole over a ten-year period increase this number of technologies 2 times, the basic industrymechanical engineering is characterized, as we can see, by a high lag. Moreover, since 2016, manufacturing industries also do not show a significant increase in the number of fundamentally new technologies created. In the field of mining, we can talk about a stable situation, measured on average by the emergence of 1-2 fundamentally new technologies. Of course, it is difficult to say how many such emerging technologies should characterize the type of activity that can be considered the most acceptable for the technological development of the industry. The comparative dynamics of nanotechnologies will be a peculiar characteristic of the development of a new technological frontier, indicating the level of application of technologies (Table 3).

Table 3. Number of nanotechnologies developed and used, 2010-2019.

\begin{tabular}{|c|c|c|c|c|c|c|c|c|c|c|}
\hline $\begin{array}{c}\text { The number } \\
\text { of } \\
\text { nanotechnolog } \\
y\end{array}$ & $\stackrel{\circ}{\stackrel{ }{ }}$ & $\overline{\bar{d}}$ & 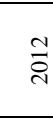 & $\stackrel{m}{\stackrel{n}{\sigma}}$ & $\stackrel{\nabla}{\stackrel{d}{\circ}}$ & $\frac{n}{\delta}$ & $\stackrel{\circ}{\stackrel{\sim}{\circ}}$ & $\bar{\sigma}$ & $\frac{\infty}{\sigma}$ & $\stackrel{\vec{े}}{\partial}$ \\
\hline Developed & 222 & 258 & 327 & 411 & 443 & 505 & 494 & 446 & 402 & 555 \\
\hline Used & 354 & 526 & 748 & 907 & 937 & 1152 & 1166 & 1144 & 1258 & 1228 \\
\hline
\end{tabular}

Source: [12]

According to table 3 , the number of developed and used nanotechnologies increased from 2010 to 2015. Since 2016 it has been declining for three consecutive years, increasing only in 2019, while the number of nanotechnologies used decreases only in 2017, then in 2019.For this type of technology, the use not only exceeds the development several times, but this gap is steadily increasing over the considered time interval.

Figure 2 shows the ratio of used and developed advanced manufacturing technologies. We can see the superiority of use over development and at the same time a significant excess of new technologies purchased over the number of developed ones. The presence of such a large line gap in Figure 2 suggests that more domestic technologies are still used, which are outdated. The share of new technologies purchased relative to the technologies used is not large. Moreover, this ratio remains stable from 2011 to 2019. Given the crisis of 2020, we can assume, taking into account the inertia of technological innovations, that this ratio will remain approximately the same in the coming years.

If technologies are not constantly improved, new ones are not created, then automatically this process, due to its very deep nature, demonstrates the property of inhibition. In an economy that is not capable of a technological race, there is a technological lag at the system level, even if there are individual technological successes.

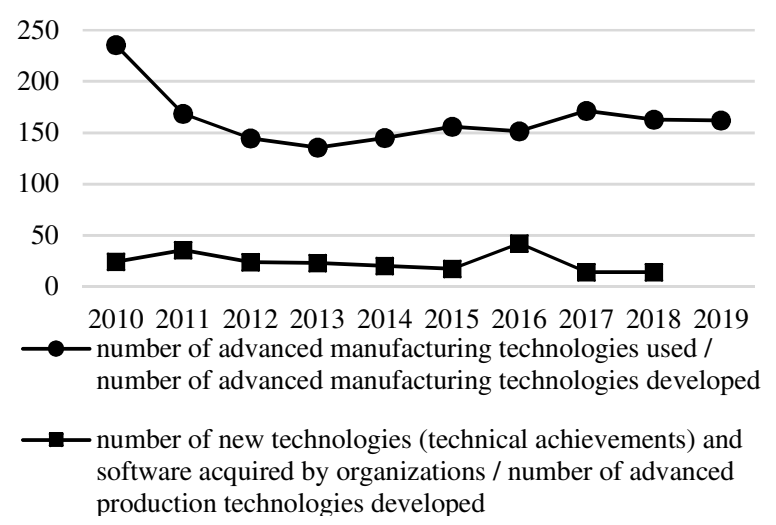

Figure 2. The ratio of used, developed and acquired advanced (new) technologies in Russia, 2010-2019.

\section{Conclusion}

Concluding the study, we note the following important positions.

First, technological dualism, which ensures the coexistence of two classes of technologies (capital and labour-intensive) and even a kind of support from one for the other, can be formed not because of technological renewal, but because of structural and inter-institutional problems of functioning and various types of activities that set the parameters for technological renewal and block technological development.

Second, the example of the Russian economy shows a pseudo-technological dualism. The released personnel from capital-intensive activities (processing) find their implementation in labour-intensive activities, but the reason for moving the resource is not the introduction of new technologies that save labour, but a high gap in the use of old and the emergence of new technologies, that is, a low level of technological renewal.

The revealed circumstance of the non-working classical effect of technological dualism, which itself arises in an already unfavourable situation of technological renewal, and the pseudo effect indicates the presence of serious problems, confirms the need to link the task of developing high-tech industries and R\&D to the structural transformation of the economy. Moreover, the purpose of this transformation should be considered the deployment of the production of new types of products and a new stock and technological base for them. The findings suggest that standard measures to encourage innovation will always be palliatives in the current situation. They can lead to some revival, but they are not able to fundamentally change the process of technological innovation and its quality. The strategy of local technological innovation, implemented in Russia, and leading to some success, however, in the strategic perspective should be replaced by a strategy of diffusion of technological innovation, which has systemic consequences and improves the functioning of many activities at the same time. Here it makes sense to 
expand Schumpeter's vision of innovation to the area of social and managerial innovation, covering the implementation of government policy.

\section{References}

1. R. Nelson, S. Winter Evolutionary theory of economic changes (Finstatinform, 2000)

2. O.S. Sukharev The theory of economic restructuring (Lenand, 2016)

3. J. A. Schumpeter Theory of economic development. Capitalism, socialism and democracy (Eksmo, 2007)

4. S. Chen, G.H. Jefferson, J. Zhang China Economic Review, 22, 133-150 (2011)

5. C. Ertur, W. Koch Interactions Journal of Economic Growth, 16, 215-255 (2011)

6. P.M. Gil, O. Afonso, P. Structural Change and Economic Dynamics, 51, 89-105(2019)

7. H. Hanusch, A. Pyka History of Economic Ideas, 15, 23-41 (2007)

8. D. Horvat, H. Kroll, A. Jäger Procedia Manufacturing, 39, 886-893 (2019)

9. K. Jati Applied Economics Letters, 8, 81-84 (2001)

10. C.G. Machado, M. Winroth, D. Carlsson,P. Almström, M. Hallin Procedia CIRP, 81, 1113-1118 (2019)

11. K.I. Westeren Foundations of the knowledge economy, 57-74 (2012)

12. Rosstat. Retrieved from: https://www.gks.ru/folder/11189. 